Vol. 1 No. 1, Maret 2021, hlm. 21 - 26

DOI: $\mathrm{xxxxxxxxxxxxxxxxx}$

Available online at http:// jurnal.stmikroyal.ac.id/index.php/j-com

\title{
PENGEMBANGAN APLIKASI KAMUS BERGAMBAR UNTUK PEMBELAJARAN ANAK BERBASIS ANDROID
}

\author{
Suri Adliani ${ }^{1}$, Fauriatun Helmiah ${ }^{2 *}$, Nurul Rahmadani ${ }^{2}$ \\ ${ }^{1}$ Mahasiswa Prodi Manajemen Informatika, STMIK Royal \\ ${ }^{2}$ Prodi Manajemen Informatika, STMIK Royal \\ *email: fauriatunh@gmail.com
}

\begin{abstract}
In the world of education, a learning medium is needed, especially in an era that is all technological, it is hoped that students from TK Kemala Bhayangkari 08 Kisaran have a learning medium that is easier to understand and can be applied, for example by applying English learning using Android-based media, The system is designed using Adobe Flash CS6 and Action Script 3.0 Android Air Pugin for Adoobe Flash CS6 as a tool for making scripts on Android which aree displayed in the form of language and attractive images and sounds, so that children can easily learn basic English and better understand with the presence of images and sound. This application should be able to develop both emotional and spiritual intelligence of children and increase children's insight in speaking English which was previously through independent learning or with other assistance for learning with Android-based English education, including images and sounds.
\end{abstract}

Keywords: Android, Learning Media, Picture Dictionary

\begin{abstract}
Abstrak: Dalam dunia Pendidikan sangat dibutuhkan sebuah media belajar, apalagi di zaman yang sudah serba teknologi maka diharapkan murid dari TK Kemala Bhayangkari 08 Kisaran memiliki suatu media belajar yang lebih mudah dipahami dan dapat diterapkan, adapun contohnya dengan mengaplikasi kan pembelajaran bahasa Inggris menggunakan media berbasis Android, sistem yang dirancang menggunakan Adobe Flash CS6 dan Action Script 3.0 Android Air Pugin for Adobe Flash CS6 sebagai bahan bantu pembuatan script pada Android yang ditampilkan dalam bentuk bahasa serta gambar yang menarik dan suara, agar anak lebih mudah dalam mempelajari bahasa Inggris dasar serta lebih memahami dengan adanya gambar dan suara. Aplikasi ini harusnya dapat mengembangkan kecerdasan baik emosional dan spiritual anak dan menambah wawasan anak dalam mengucapkan bahasa Inggris, yang tadinya dengan cara belajar mandiri atau dengan pendampingan lain untuk pembelajaran dengan edukasi bahasa Inggris yang berbasis Android disertakan gambar dan suara.
\end{abstract}

Kata Kunci : Android, Kamus Bergambar, Media Pembelajaran 
Vol. 1 No. 1, Maret 2021, hlm. 21 - 26

DOI: $\mathrm{xxxxxxxxxxxxxxxxx}$

Available online at http:// jurnal.stmikroyal.ac.id/index.php/j-com

\section{PENDAHULUAN}

Bahasa merupakan salah satu bentuk komunikasi manusia dan dimasa sekarang ini, sehubungan dengan berkembangnya zaman maka setiap orang dituntut harus bisa mengikuti perkembangannya seperti contohnya keahlian dalam menguasai Bahasa inggris yang di pergunakan dalam dunia internasional, pembelajaran ini utamanya harus dimulai sejak usia sekolah dasar, pada tingkatan ini Pendidikan anak masih tergolong kedalam kelompok bermain. Proses perkembangan anak-anak tersebut di usia ini dipastikan mampu menyerap secara teoritis materi pembelajaran yang diberikan di sekolah, hal itu membutuhkan intelegensi berupa daya pikir, daya cipta, kecerdasan emosi dan spiritual dengan aspek social emosional dan bahasa yang digunakan sesuai pertumbuhan dan perkembangannya.

Pendidikan anak pada usia 2-4 tahun masuk pada Kelompok Bermain (KB) ini layaknya seperti belajar sambal bermain. Sosok individu ini sedang menjalani suatu proses perkembangan dengan pesat dan fundamental bagi kehidupan selanjutnya dalam hal ini untuk mengasah kemampuan komunikasi, bahasa dan lain sebagainya yang berkaitan dengan intelegensi anak [1].

Teknologi sudah memberikan kemudahan pada setiap orang dan telah menjadi kebutuhan seperti aplikasi berbasis android. Aplikasi yang berkaitan dengan edukasi ataupun pendidikan berbasis android lebih menarik untuk anak-anak dan lebih mudah untuk mempelajarinya [2].

\section{METODE}

\section{Media Pembelajaran}

Media pembelajaran merupakan segala bentuk alat yang dapat membantu penyampaian materi pelajaran dalam proses belajar mengajar agar dapat memudahkan pencapaian tujuan dari apa yang dirumuskan [3].

\section{Pengertian Multimedia}

Multimedia adalah sebuah sarana melalui penggunaan komputer dengan menggabungkan dan menampilkan suara, teks, animasi, audio dan video menggunakan alat bantu dan koneksi yang memudahkan pengguna dalam membuat sebuah karya [4].

\section{Gambar dan Grafik}

Gambar sangat berperan penting dalam multimedia, gambar diekspresikan dalam bentuk gambar diam, lukisan atau foto yang diambil melalui kamera digital. Titik-titik (dot) dimana gambar dicontohkan dikenal sebagai elemen gambar, biasanya disingkat sebagai piksel (pixel). Nilai intensitas piksel gambar disebut tingkat gradasi abu-abu (grayscale) [5]. 
Vol. 1 No. 1, Maret 2021, hlm. 21 - 26

DOI: $\mathrm{xxxxxxxxxxxxxxxxx}$

Available online at http:// jurnal.stmikroyal.ac.id/index.php/j-com

\section{Suara/Audio}

Suara yaitu getaran yang dihasilkan dari sebuah gesekan atau pantulan antara benda sementara audio dihasilkan oleh getaran suatu benda, supaya dapat tertangkap oleh telinga maka getaran tersebut harus kuat.

\section{Animasi dalam Multimedia}

Animasi merupakan penggunakan komputer untuk menciptakan gerak pada layar. Ada 9 (sembilan) macam animasi, yaitu animasi sel, animasi frame, animasi sprite, animasi lintasan, animasi spline, animasi vektor, animasi karakter, animasi computational, dan morphing.

\section{Software dan Data}

Salah satu konsep paling ampuh dalam multimedia adalah ketergantungan serempak yang dapat dicapai dengan menciptakan link keberbagi dokumen dan dataset. Saat pemakaian memicu satu link ke suatu dokumen word processor, seperti file.doc, di Microsoft Word misalnya, maka komputer akan secara otomatis meluncurkan aplikasi perangkat lunak (pada contoh ini MS.Word) dan menggunakannya untuk menampilkan dokumen yang dimaksud. Begitu pula, sebuah link ke sebuah file.xls di Excel untuk menampilkan spreadsheet tersebut.

\section{HASIL DAN PEMBAHASAN}

Arah dari perancangan sistem ini adalah untuk mempermudah proses penyampaian yang dilakukan dalam proses pembelajaran bagi anak-anak dalam mempelajari Bahasa Inggris dasar dengan tampilan bergambar.

Dari analisis yang dilakukan dapat kita lihat peluang yang sangat baik bagi peningkatan efektivitas dalam belajar, sebaiknya menerapkan dan memakai sistem yang baru secara optimal pada proses penyampaian agar menghasilkan informasi yang dibutuhkan menjadi lebih baik. Sistem yang diusulkan ini merupakan rancangan baru yang dilakukan sebagai pengimplementasian dari aplikasi yang telah dirancang.

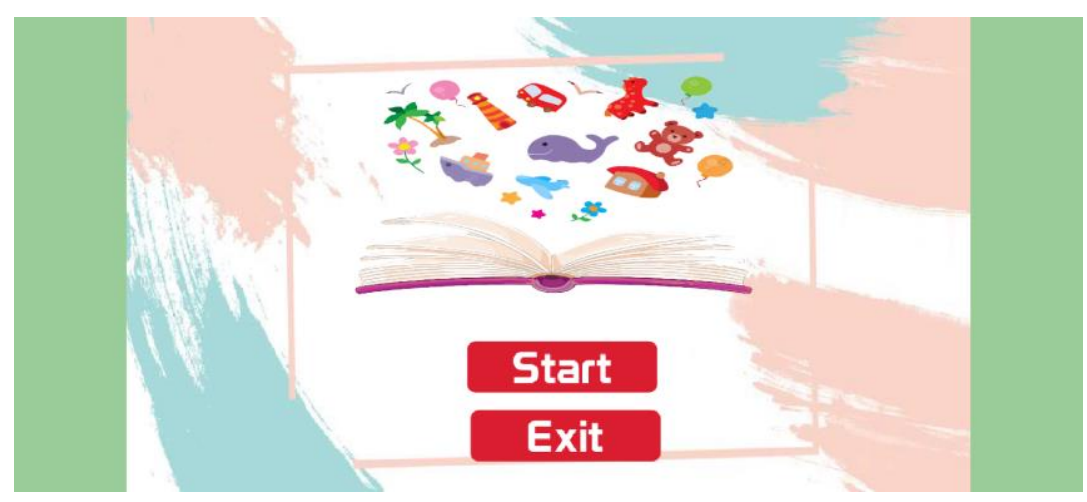

Gambar 1. Proses Pengeditan Background 
Vol. 1 No. 1, Maret 2021, hlm. 21 - 26

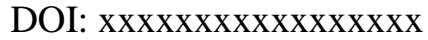

Available online at http:// jurnal.stmikroyal.ac.id/index.php/j-com

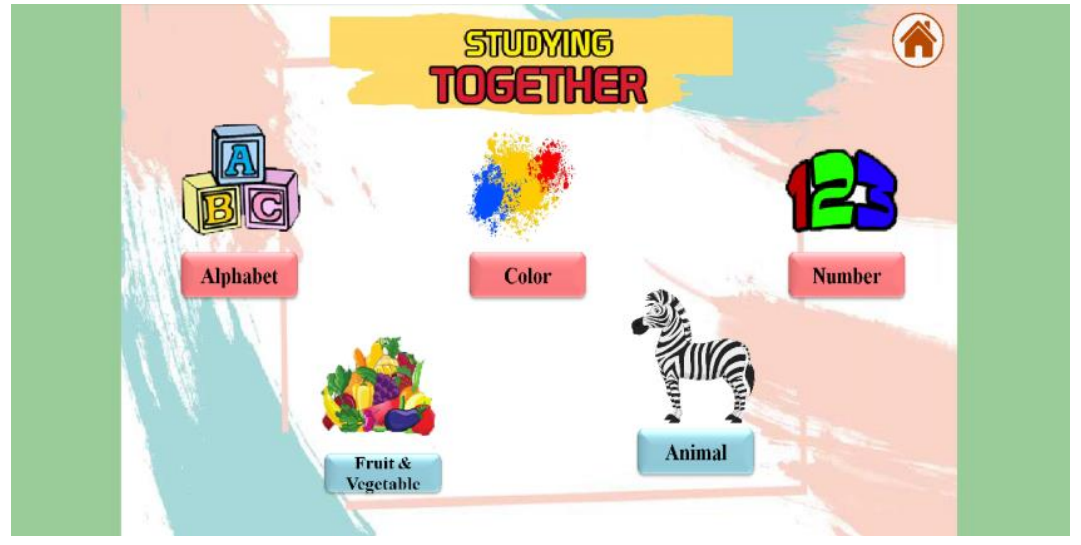

Gambar 2. Menu Pilihan

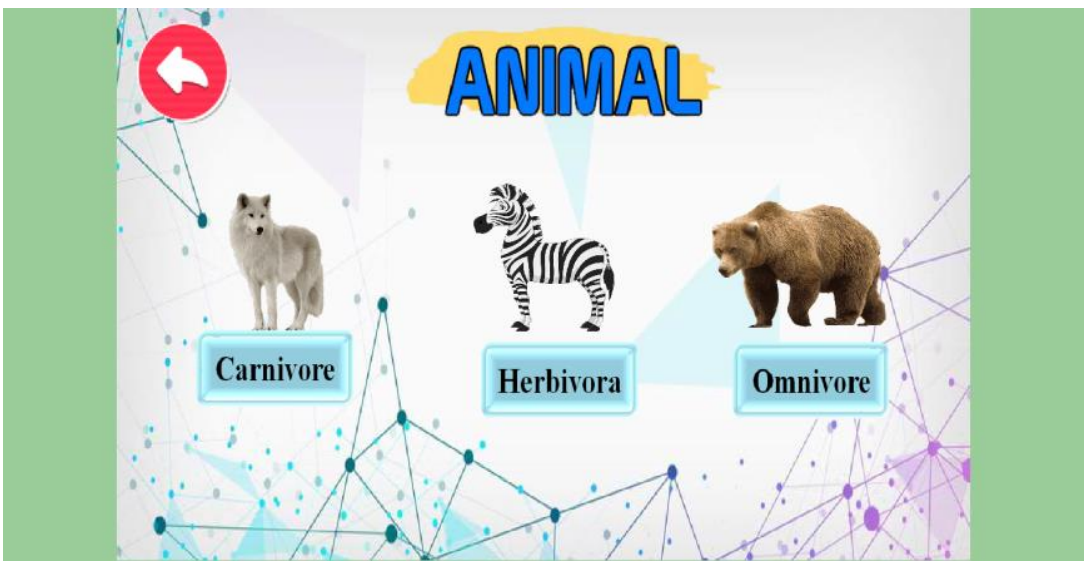

Gambar 3. Pembuatan Materi

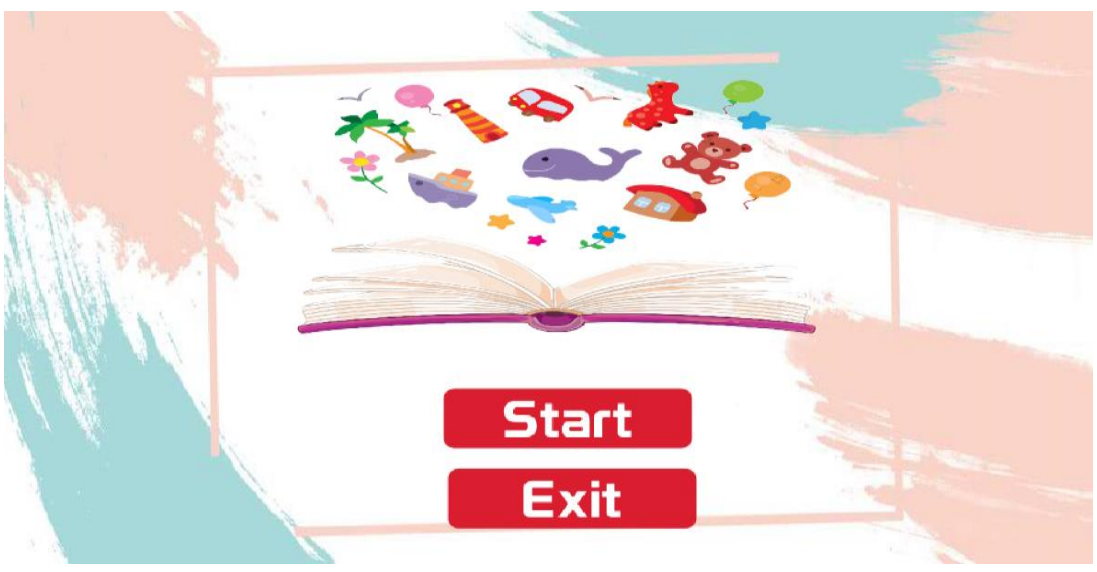

Gambar 4. Tampilan Dashboard 
Vol. 1 No. 1, Maret 2021, hlm. 21 - 26

DOI: $\mathrm{xxxxxxxxxxxxxxxxx}$

Available online at http:// jurnal.stmikroyal.ac.id/index.php/j-com

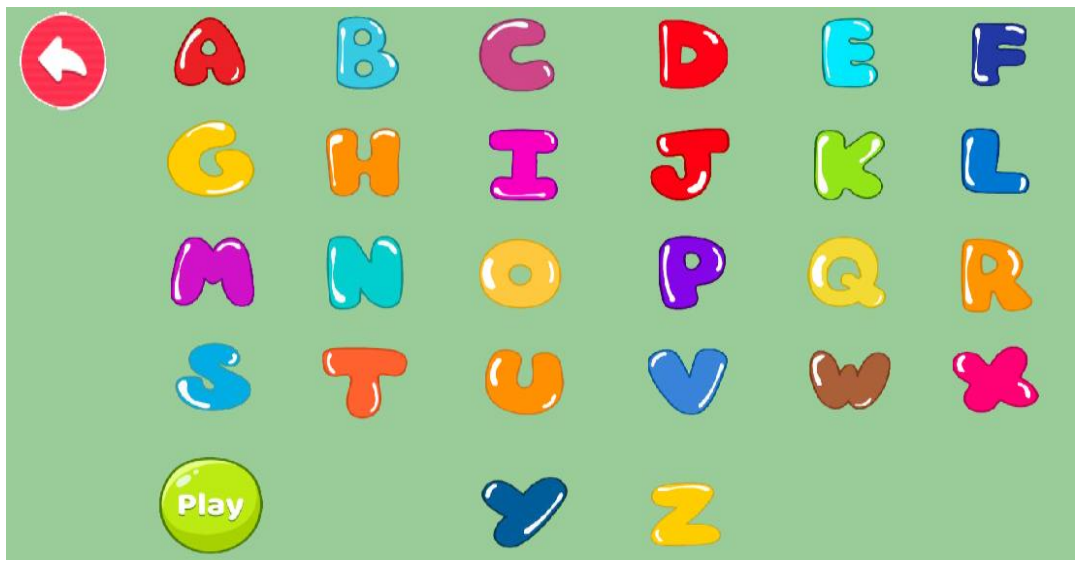

Gambar 5. Halaman Alphabets

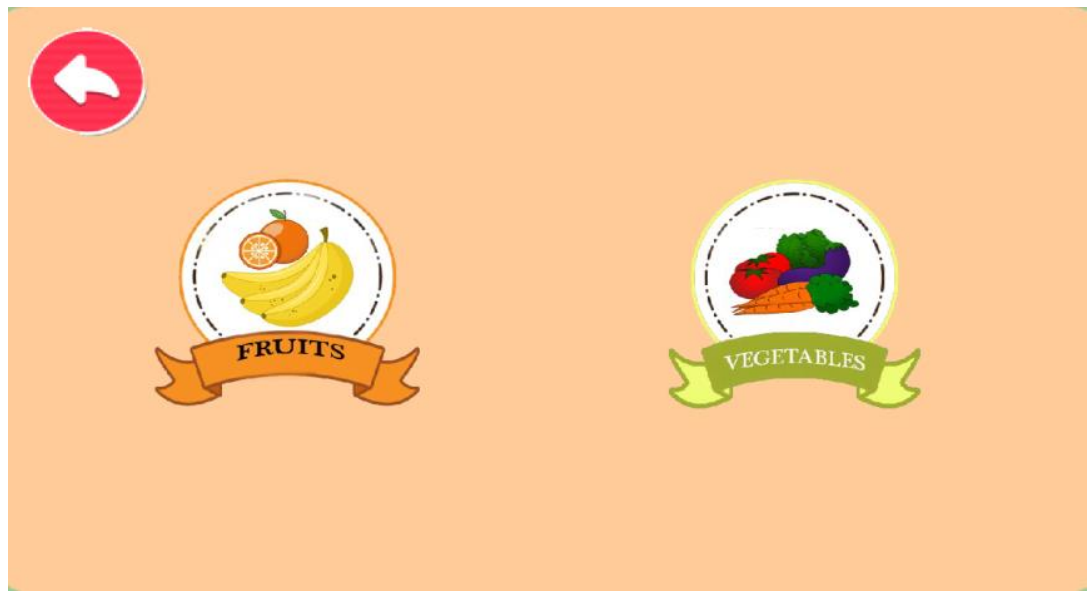

Gambar 6. Fruits \& Vegetables

\section{SIMPULAN}

Berdasarkan hasil penelitian, analisa selama melakukan laporan pada TK Kemala Bhayangkari 08 Kisaran adalah: (1) Pada TK Kemala Bhayangkari 08, sistem pembelajaran dan pemberian materi bahasa Inggris masih dilakukan secara konvensional sehingga diperlukan perbaikan terhadap sistem tersebut menjadi sistem media edukasi bahasa Inggris berbasis android yang lebih efektif dan efisien., (2) Dengan menggunakan bahasa pemograman Adobe Flash CS6 dalam pembuatan edukasi pembelajaran bahasa Inggris maka pembelajaran akan lebih mudah dan lebih dapat dipahami oleh siswa karena terdapat gambar serta suara pada edukasi berbasis Android., (3) Mempermudah para Pengajar dalam memberikan penjelasan dan pembelajaran bahasa Inggris kepada siswa, karena lebih mudah dipahami oleh siswa dikarenakan terdapat gambar dan suara pada edukasi berbasis Android ini. 
Vol. 1 No. 1, Maret 2021, hlm. 21 - 26

DOI: $\mathrm{xxxxxxxxxxxxxxxxx}$

Available online at http:// jurnal.stmikroyal.ac.id/index.php/j-com

\section{DAFTAR PUSTAKA}

[1] Saurina, N. (2016). Pengembangan Media Pembelajaran Untuk Aanak Usia Dini Menggunakan Augmented Reality. Jurnal IPTEK Vol.20 No.1 , 96.

[2] Wahyudin, Romansyah, A., \& Lauryn, M. S. (2015). Perancangan Aplikasi Edukasi Pengenlan Bahasa Inggris Berbasis Android Pada TK An-Nasir Tangerang. Jurnal PROSISKO Vol.2 No.1 , 88.

[3] Syamsiah. (2017). Pengembangan Aplikasi Multimedia Pembelajaran Interaktif Untuk Mata Pelajaran Bahasa Indonesia. Jurnal SAP Vol. 2 No. 1 , 55-56.

[4] Marianda, G., Johar, A., \& Risdianto, E. (2015). Rancangan Bangun Media Pembelajaran Berbasis Multimedia Interaktif Konsep Gaya Pada Mata Pelajaran Fisika SMP Kelas VIII. Jurnal Rekursif, Vol. 2 No. 2 , 114.

[5] Simarmata, J., \& Mujiarto. (2019). Multimedia Pembelajaran. Jl. Gegerkalong Hilir No. 84 Bandung: ALFABETA, cv. 